\title{
BMJ Open Patients' experiences of deep brain stimulation for Parkinson's disease: a qualitative systematic review and synthesis
}

\author{
J Mathers, ${ }^{1}$ C Rick, ${ }^{1}$ C Jenkinson, ${ }^{2}$ R Garside, ${ }^{3}$ H Pall, ${ }^{4}$ R Mitchell, ${ }^{5}$ S Bayliss, ${ }^{1}$ \\ L L Jones ${ }^{1}$
}

To cite: Mathers J, Rick C, Jenkinson C, et al. Patients' experiences of deep brain stimulation for Parkinson's disease: a qualitative systematic review and synthesis. BMJ Open 2016;6:e011525. doi:10.1136/bmjopen-2016011525

- Prepublication history and additional material is available. To view please visit the journal (http://dx.doi.org/ 10.1136/bmjopen-2016011525).

Received 17 February 2016 Revised 22 April 2016 Accepted 26 May 2016 CrossMark

\footnotetext{
${ }^{1}$ Institute of Applied Health Research, University of Birmingham, Birmingham, UK ${ }^{2}$ Nuffield Department of Population Health, University of Oxford, Oxford, UK

${ }^{3}$ European Centre for Environment and Human Health, University of Exeter, Exeter, UK

${ }^{4}$ Institute of Clinical Sciences, University of Birmingham, Birmingham, UK

${ }^{5}$ Department of Neurosurgery, University Hospitals Birmingham NHS Foundation Trust, Birmingham, UK
}

Correspondence to Dr J Mathers; j.m.mathers@bham.ac.uk

\section{ABSTRACT}

Objective: To review and synthesise qualitative research studies that have explored patients' experience of deep brain stimulation (DBS) in advanced Parkinson's disease (PD).

Design: Systematic review and meta-synthesis of 7 original papers, using metaethnography.

Setting: Studies conducted in Denmark, France and Sweden.

Participants: 116 patients who had undergone DBS and 9 spouses of patients.

Results: Prior to surgery, the experience of advancing $P D$ is one of considerable loss and a feeling of loss of control. There are significant hopes for what DBS can bring. Following surgery, a sense of euphoria is described by many, although this does not persist and there is a need for significant transitions following this. We suggest that normality as a concept is core to the experience of DBS and that a sense of control may be a key condition for normality. Experience of DBS for patients and spouses, and of the transitions that they must undertake, is influenced by their hopes of what surgery will enable them to achieve, or regain (ie, a new normality).

Conclusions: There is a need for further qualitative research to understand the nature of these transitions to inform how best patients and their spouses can be supported by healthcare professionals before, during and after DBS. In assessing the outcomes of DBS and other treatments in advanced PD, we should consider how to capture holistic concepts such as normality and control. Studies that examine the outcomes of DBS require longer term follow-up.

\section{INTRODUCTION}

Deep brain stimulation (DBS) is widely used to treat a range of Parkinson's disease (PD) symptoms, typically in advanced PD, although its efficacy has been tested in earlier stages. ${ }^{1}$ DBS is effective in improving many motor and some non-motor symptoms. Meta-analysis $^{2}$ of six randomised controlled

\section{Strengths and limitations of this study}

- This is the first review and synthesis of qualitative research examining patients' experience of deep brain stimulation for Parkinson's disease.

- The synthesis identifies core overarching concepts that facilitate our understanding of the experience of deep brain stimulation.

- Two papers were of low quality based on methodological reporting but were conceptually rich.

- To date, only seven qualitative studies focusing on the experience of deep brain stimulation have been undertaken.

trials (RCTs) of DBS demonstrates significant improvements in motor disability, activities of daily living, medication use, mental health, mood, behavioural problems and quality of life (QoL). However, measures of communication, dementia and executive functioning favoured medication controls.

Despite the overall effectiveness of DBS, observational studies and subgroup analyses of trial data demonstrate that not all patients report improvements in QoL. Daniels $e t a \hat{l}$ found that $43 \%$ of patients showed no improvement at 6 months, and Soulas $e t a l^{4}$ found that $37 \%$ showed no improvement or a decline in QoL. For composite indices and individual domains of global disease specific (eg, Parkinson's Disease Questionnaire (PDQ)-39), and generic QoL measures, there are aggregate improvements in motor signs, mobility, activities of daily living, stigma and bodily discomfort, but no improvement or decline in social support, emotional wellbeing, cognition and communication. ${ }^{4-7}$ Studies that have quantified patients' and spouses' perceived outcome at 3 months postsurgery show positive ratings in only $47 \%$ and $33 \%$ of patients and spouses, respectively. ${ }^{8}$ Other studies have examined the 
clinical, demographic and psychosocial factors that might influence outcomes such as QoL post-DBS. Factors that have been associated with these outcomes include age, depression/emotional distress, apathy, levodopa response, time spent in off periods, time since disease onset and a history of impulse control disorders or compulsive medication use, although findings remain inconclusive. ${ }^{347910}$

Most research informing debates about the efficacy and use of DBS is quantitative, using measurement and ratings scales. Although Maier $e t a l^{\dagger}$ and Lewis $e t a l^{\beta}$ used qualitative data collection methods (interviews) with patients and spouses, their accounts were quantified to categorise participants into positive or negative outcome assessments. The only commonly cited exception to this is the study by Agid $e t a l^{11}$ which used semistructured psychological interviews to explore contrasts in perspectives on improvement post-DBS between clinicians, patients and spouses.

Qualitative research provides in-depth description, understanding and explanation of patients' experience of disease and treatment. The value of qualitative evidence as an adjunct to RCTs is well recognised, with examples of qualitative research being used to contextualise and understand trial observations. ${ }^{12}$ Paralleling meta-analysis for quantitative studies, qualitative synthesis techniques have been developed to analyse the findings of primary qualitative research, to identify commonality and difference in findings, and to arrive at higher order interpretations and explanation of the subjective experience of disease and treatment from a patient perspective. ${ }^{13}$ We sought to synthesise existing qualitative research that has examined patients' experiences and perspectives related to DBS. In doing so, we wished to examine whether this research might provide some further insight into the variable and often negative assessment of QoL given by patients and spouses soon after DBS, despite the apparent overall effectiveness of the procedure as measured in RCTs.

\section{METHODS}

\section{Literature searches}

Several strategies were employed to maximise the identification of relevant literature. ${ }^{14}{ }^{15}$ These included searching electronic databases (MEDLINE, MEDLINE In Process and EMBASE via Ovid); CINAHL via EBSCO; Social Sciences Citation Index and Conference Proceedings Citation Index (CPCI) via Web of Science and CENTRAL Trials Register; the Database of Abstracts of Reviews of Effects; and Health Technology Assessment Database all via Cochrane Wiley). Conference abstracts were searched via CPCI (see above) and British Library's ZETOC and authors of conference abstracts contacted. Reference lists of included papers were also searched.

\section{Selection criteria}

English language papers published in peer-reviewed journals, which reported using qualitative methodology to explore patients' or spouses' experiences of DBS for the treatment of advanced PD, were included. We included research (one paper) reporting spouses' perspectives as it can help to illuminate the experiences of patients. The searches (see online supplementary appendix 1 for an example) applied no date limits (ie, went back to inception for each database and were run to the end of February 2015). Searches were part of a wider project and covered the broader topic of patients' and spouses' experience of living with PD. A focus on DBS was required for this subproject, and relevant papers were highlighted during the wider screening process. Papers had to report results of qualitative analysis based on qualitative data collection methods (eg, interviews, focus groups, observations). We included multiple papers from the same data set as long as they reported the interpretation of different research questions. Editorials, narrative reviews and papers which reported the experience of living with advanced PD but not specifically in relation to DBS were excluded.

\section{Screening}

Following the removal of duplicates, the titles and abstracts of identified articles were screened, with exclusion of those not meeting the above selection criteria. Full-text versions of the remaining articles were reviewed by two authors (JM and LLJ) and the list of papers to be included in the synthesis finalised via consensus discussion (figure 1).

\section{Quality assessment}

There remains significant discussion in the literature around quality appraisal of studies included in qualitative syntheses. In particular, there are debates about the meaning of quality and validity, how to incorporate the findings of studies considered to be of lower quality, and the uncritical use of quality checklists. ${ }^{16}{ }^{17}$ We assessed both the methodological reporting and robustness of each study using the Critical Appraisal Skills Programme (CASP) Qualitative Checklist, ${ }^{18}$ and also their conceptual richness. Following this process, it was decided that all of the identified studies would be adopted in the current synthesis. Two studies ${ }^{11} 19$ which we rated as low quality in terms of reporting (eg, due to a lack of specified detail regarding recruitment of participants and analytical approach) were rated highly in terms of their conceptual richness. ${ }^{20}$

\section{Data extraction}

Key characteristics of studies (table 1) were extracted independently by two authors (JM and LLJ), quality checked and discrepancies resolved via discussion, ready for comparative analysis. For each included study, the following were extracted: authors, title, journal, year of publication, setting, stated aims and focus, participant 


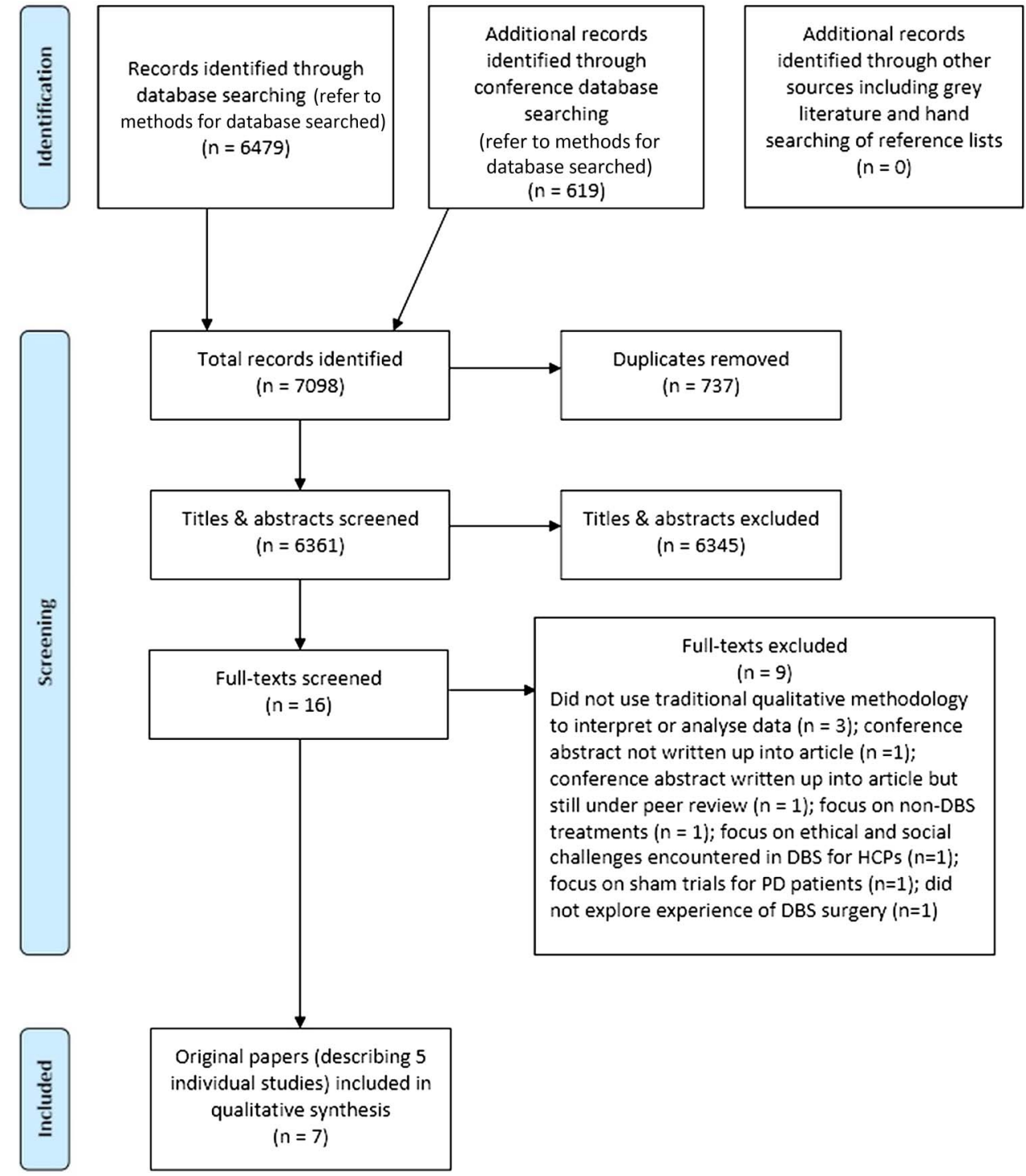

Figure 1 Flow diagram of included and excluded studies. DARE, Database of Abstracts of Reviews of Effects; DBS, deep brain stimulation; HTA, Health Technology Assessment; PD, Parkinson's disease; SSCI, Social Sciences Citation Index.

characteristics, data collection method/s, data collection time point in relation to DBS, method of analysis, themes and subthemes presented, and study author interpretations of data presented. Participant quotations were also extracted.

\section{Analysis}

Metaethnography ${ }^{20}$ was used to identify, translate and interpret shared concepts across the papers. The aim of this approach is interpretive rather than aggregative, and thus is concordant with the paradigm that underpins the majority of primary qualitative research that syntheses are based on. ${ }^{21}$ Metaethnography is the longest established tool for synthesising qualitative research, ${ }^{13}{ }^{22}$ and has been used with smaller bodies of literature and, despite its label and origins, with non-ethnographic studies. ${ }^{23}$ We broadly followed the seven-step process proposed by Noblit and Hare ${ }^{20}$ and also used in a worked healthcare example by Britten et $a l^{21}$ (1) getting started; (2) deciding what is relevant to the initial interest; (3) reading the studies; (4) determining how the studies are related; (5) translating the studies into one another; (6) synthesising translations and (7) expressing the synthesis. Each paper, in the form of the extracted document (first and second order constructs), was annotated in detail by JM and LLJ and then core concepts and the interpretation of these discussed at length to develop the line of argument presented in this paper. Core concepts were mapped across the papers to ensure that convergent and divergent cases were considered. However, it became clear that the studies were broadly concordant and suitable for the reciprocal translation that underpins the line of argument developed. The paper by Haahr et $a l^{24}$ was used as an index paper to help facilitate the translation of studies into each other as it was judged to be both conceptually rich and well reported. ${ }^{20}$ 
Table 1 Key characteristics of included papers

\begin{tabular}{|c|c|c|c|c|c|c|c|}
\hline $\begin{array}{l}\text { First } \\
\text { author }\end{array}$ & $\begin{array}{l}\text { Year } \\
\text { published }\end{array}$ & Country & Study focus/aim* & Participants & $\begin{array}{l}\text { Data collection } \\
\text { method }\end{array}$ & $\begin{array}{l}\text { Data collection } \\
\text { time point }\end{array}$ & Analysis method \\
\hline $\begin{array}{l}\text { Haahr } \\
\text { et } a l^{27}\end{array}$ & 2013 & Denmark & $\begin{array}{l}\text { To explore the lived } \\
\text { experience of being a spouse } \\
\text { to a person living with } \\
\text { advanced PD, before and } \\
\text { during the first year of DBS }\end{array}$ & $\begin{array}{l}9 \text { spouses of patients } \\
\text { with PD; } 3 \text { men, } 6 \\
\text { women; mean age of the } \\
\text { spouses at their partners' } \\
\text { disease onset } 46 \text { years } \\
\text { (range } 27-61 \text { ); mean age } \\
\text { of the spouses at the } \\
\text { time of their partners' } \\
\text { treatment with DBS } \\
61 \text { years (range } 41-76 \text { ) }\end{array}$ & $\begin{array}{l}\text { Audio recorded } \\
\text { longitudinal qualitative } \\
\text { in-depth interviews }\end{array}$ & $\begin{array}{l}\text { Pre-DBS and } \\
\text { post-DBS at } 4 \\
\text { time points: } 2-4 \\
\text { weeks prior to } \\
\text { surgery, } 6 \text { weeks, } \\
6 \text { months and } \\
12 \text { months after } \\
\text { surgery }\end{array}$ & $\begin{array}{l}\text { Thematic analysis } \\
\text { influenced by the } \\
\text { hermeneutic } \\
\text { phenomenological } \\
\text { methodology of van } \\
\text { Manen }\end{array}$ \\
\hline Gisquet $^{19}$ & 2008 & France & $\begin{array}{l}\text { To understand the personal, } \\
\text { familial and professional } \\
\text { difficulties experienced by } \\
\text { patients in France who have a } \\
\text { neurodegenerative disease } \\
\text { and undergo cerebral } \\
\text { implants }\end{array}$ & $\begin{array}{l}30 \text { participants; } 17 \text { men, } \\
13 \text { women; age range } \\
39-79 \text { years }\end{array}$ & $\begin{array}{l}\text { Audio recorded } \\
\text { cross-sectional } \\
\text { interviews }\end{array}$ & $\begin{array}{l}\text { Pre-DBS and } \\
\text { post-DBS at } 3 \\
\text { time points: prior } \\
\text { to surgery, } 1 \text { day } \\
\text { to } 6 \text { months and } \\
\text { at least } 2 \text { years } \\
\text { after surgery }\end{array}$ & Thematic analysis \\
\hline $\begin{array}{l}\text { Haahr } \\
\text { et }\left.a\right|^{24}\end{array}$ & 2010 & Denmark & $\begin{array}{l}\text { To explore and describe the } \\
\text { lived experience of patients } \\
\text { living with advanced PD } \\
\text { during the first year of } \\
\text { treatment with DBS }\end{array}$ & $\begin{array}{l}9 \text { participants }+ \text {; } 6 \text { men } \\
\text { and } 3 \text { women; mean age } \\
\text { at DBS } 61 \text { years (range } \\
47-67 \text { ); } \\
\text { mean disease duration } \\
15 \text { years (range } 7-29 \text { ) }\end{array}$ & $\begin{array}{l}\text { Audio recorded } \\
\text { longitudinal qualitative } \\
\text { in-depth interviews }\end{array}$ & $\begin{array}{l}\text { Post-DBS at } 3 \\
\text { time points: } 6- \\
8 \text { weeks, } 6 \text { and } \\
12 \text { months after } \\
\text { surgery }\end{array}$ & $\begin{array}{l}\text { Guided by the } \\
\text { hermeneutic } \\
\text { phenomenological } \\
\text { methodology of van } \\
\text { Manen }\end{array}$ \\
\hline $\begin{array}{l}\text { Ahlberg } \\
\text { et }\left.a\right|^{25}\end{array}$ & 2011 & Sweden & $\begin{array}{l}\text { To explore perspectives of } \\
\text { the way patients speech and } \\
\text { communication changed as a } \\
\text { result of subthalamic nucleus } \\
\text { DBS treatment for PD }\end{array}$ & $\begin{array}{l}4 \text { participants; } 2 \text { men, } \\
2 \text { women; aged } 61- \\
79 \text { years; years since } \\
\text { onset } 10-32 \text { years }\end{array}$ & $\begin{array}{l}\text { Video recorded } \\
\text { cross-sectional } \\
\text { semistructured } \\
\text { interviews in the } \\
\text { participant's home }\end{array}$ & $\begin{array}{l}\text { Post-DBS at } 1 \\
\text { time point: at } \\
\text { least } 2 \text { years after } \\
\text { surgery (range } 2- \\
10 \text { years) }\end{array}$ & $\begin{array}{l}\text { Qualitative content } \\
\text { analysis }\end{array}$ \\
\hline
\end{tabular}




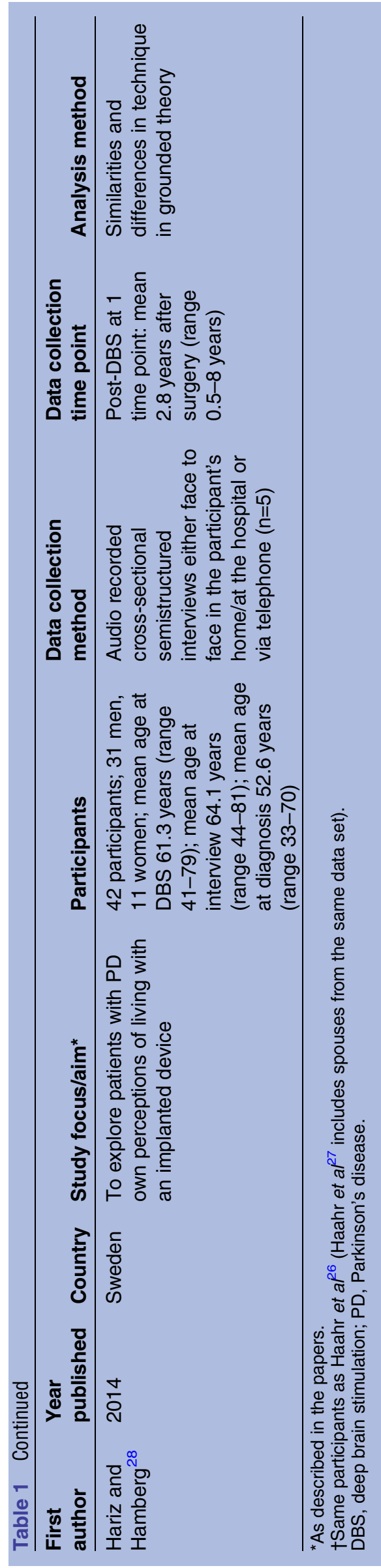

RESULTS

Summary of included papers

Seven papers ${ }^{11} 19$ 24-28 describing five studies are included (table 1). Six explore patients' $(n=116)^{11} 1924-2628$ and one spouses' experiences $(n=9){ }^{27}$ Three $^{24} 2627$ report novel aspects from one data set. Studies reported participants' experiences pre-DBS, ${ }^{26}$ pre-DBS and post-DBS, $^{11} 1927$ or post-DBS ${ }^{24} 25 \quad 28$ using crosssectional $^{25} 2628$ or longitudinal interview data. ${ }^{11} 192427$ Three collected data in Denmark, ${ }^{24} 26 \quad 27$ two in France $^{1119}$ and two in Sweden. ${ }^{2528}$

\section{THE EXPERIENCE OF DBS AND PD}

Only one paper ${ }^{26}$ provides an explicit focus on life prior to late stage PD and consideration of DBS. We will not describe these data or other qualitative research focusing on the experience of living with PD outside the context of DBS in detail as it has been summarised previously. $^{29}$

We provide a brief descriptive overview of the chronology of experience of DBS, before a detailed description of the core cross-cutting themes (normality, loss, loss of control, transitions, hopes) in our interpretation of this chronology (table 2). These themes are highlighted in bold in the text.

\section{THE CHRONOLOGY \\ Pre-DBS}

There is a need for higher dosage and more frequent medication with advancing PD and life is increasingly focused on the disease and treatment. ${ }^{27}$ Although patients are able to maintain some control via medication, this time of gradual disease progression is described as a period of considerable loss (figure 2 ). ${ }^{11} 19$ 24-27

Eventually, advanced PD is characterised by unpredictability and a feeling of loss of control ${ }^{1924-28}$ as the effectiveness of medication diminishes. Studies that present data on pre-DBS perspectives indicate that surgery is viewed as a 'last resort'11 192526 and that the choice to undergo DBS is not much of a choice at all:

I was ready for an operation when the rigidity and the dyskinesia superseded each other, so that I did not get any good time in between. (Patient ${ }^{25}$ )

There appear to be significant hopes ${ }^{19}$ 24-28 for what the surgery can bring, hopes that are influenced by this experience of loss and loss of control.

\section{Post-DBS}

Immediately postsurgery, a sense of euphoria 1119252728 is reported by many patients, resulting from the new found (or regained) sense of freedom initially afforded by the procedure. Haahr et $a l^{24}$ indicate that this persists for some, but collectively the evidence describes a need for significant transitions to a new disease state and life, following this initial euphoria. Although Haahr et $a l^{24}$ 
Table 2 Presence of core cross-cutting themes interpreted within the chronology for each study

\begin{tabular}{|c|c|c|c|c|c|}
\hline Reference & Loss & Loss of control & Hope & Normality & Transitions \\
\hline Haahr et $a$ P $^{4 \star}$ & Yes (in Haahr et $a^{26}$ ) & Yes & Yes & Yest & Yes \\
\hline Haahr et $a{ }^{77}$ & Yes & Yest & Yes & Yes & Yes \\
\hline Haahr et $a^{26}$ & Yes & Yes & Yes & $\begin{array}{l}\text { Not } \\
\text { covered }\end{array}$ & NAł \\
\hline Gisquet $^{19}$ & Yes & $\begin{array}{l}\text { Yes-core concept in } \\
\text { paper }\end{array}$ & Yes & Yest & Yes \\
\hline Ahlberg et $a^{25}$ & $\begin{array}{l}\text { Yes (but postsurgery loss associated } \\
\text { with voice) }\end{array}$ & Yest & Yes & Yest & Yes \\
\hline $\begin{array}{l}\text { Hariz and } \\
\text { Hamberg }^{28}\end{array}$ & Not covered & Yes & Yes & Yest & Yes \\
\hline Agid et al ${ }^{11}$ & Yes & Not covered & $\begin{array}{l}\text { Not } \\
\text { covered }\end{array}$ & Yest & Yes \\
\hline
\end{tabular}

suggest that patients and spouses can find a clear resolution with their new disease state and life post-DBS, it is unclear whether all, or what proportion of patients manage successful transitions. However, those papers that report an overall assessment indicate that, although not uncomplicated, over time, the overall impacts of the surgery are judged positively by patients. ${ }^{28}$

\section{CORE THEMES AND THEIR INTER-RELATIONSHIP}

Our interpretation is that normality as a concept is a core component of the experience of DBS and the meaning of that for patients. In turn, control may be a key condition for a sense of normality, with loss of control precluding that. Experience of DBS and the transitions post-DBS link to hopes that the surgery will allow people to achieve, or regain, normality in life. In turn, this should be understood within the context of the seemingly irrevocable loss and loss of control that patients, spouses and those around them experience during late stage PD.

\section{Normality}

Normality $^{11} 19242452728$ is a concept present in the descriptive accounts of findings, in the primary data reported, and implicitly as the goal that patients and spouses strive towards during the transitions that they undergo post-DBS. We propose that normality has a dual meaning. First, normality as a state can be opposed to the diseased state and the impacts of that diseased state, that is, it represents a prediseased life. Patients seek to maintain this using medication in the early stages of PD, via control of the disease and its impacts. However, as PD progresses, normality is also a descriptor for a state whereby patients are able to maintain an adjusted life which accommodates the disease. Normality is conditional on perceived control over the disease and its management. In other words, loss of control, an inability to predict and manage the impacts of the disease, means that patients and spouses can no longer maintain any sense of normality:

More than half of the couples experienced that nothing was 'normal' for a long period of adjustment [to stimulation]. This put a strain on both parties and on their relationship. (Author interpretation ${ }^{27}$ )

\section{Loss and loss of control}

Progressive PD results in loss. Impacts include impaired physical function and ability to do things; unpredictability of everyday life and the associated inability to plan ahead (loss of freedom); weakened social ties, friendships and relationships; loss of time as medication

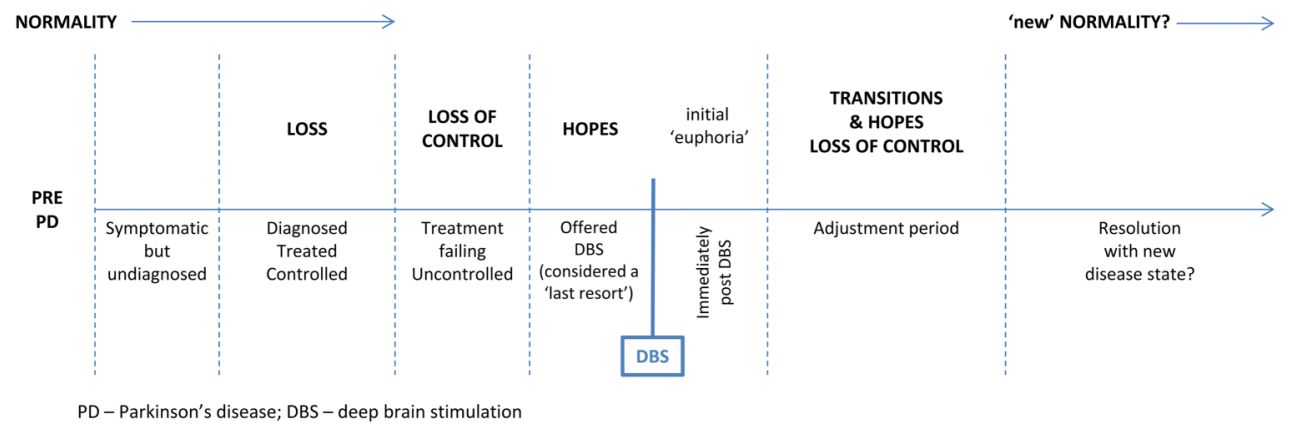

Figure 2 Chronology of patient's and spouses' experiences of Parkinson's disease and deep brain stimulation. 
regimes are predominant; and loss of elements of relationships with spouses, for example, intimacy, joint activities, independence and time for oneself, companionship. ${ }^{11} 1924-27$

There has been loss of many things. Loss of the person you married, loss of abilities, loss of strength...I have experienced social isolation. Having to find a new identity, a new social life, a new way of living life...we have talked about what possibilities we have. How can we compensate for what we have lost? (Spouse ${ }^{27}$ )

Late stage PD is characterised by perceived loss of control over the disease and impacts of disease. There is an increased lack of predictability. The resultant fear of negative consequences of this loss of control (eg, going off in public) places further constraints on patients and spouses. The condition (control) that allows maintenance of some sense of normality is removed from their grasp, so that even 'a new identity, social life and way of living', as described above, ${ }^{27}$ is compromised.

The ability to attain some perceived control post-DBS may be crucial to transitions that must be undertaken in order to allow patients and spouses to attain some sense of a (new) normality.

\section{Transitions}

Following the initial postsurgery euphoria, ${ }^{11} 19^{25-28}$ for many, there is a need to undergo wide ranging transitions $^{11} 1924252728$ in order to adjust to a post-DBS life. Some patients report this as a decline, although it is unclear whether this is a genuine physical decline or a manifestation of the realisation that DBS necessitates complex transitions. These transitions are physical and bodily, functional and activity-related, social and relationships, and psychological.

Physical and bodily transitions include the need for adjustments in stimulation parameters in order to establish 'optimal' settings in conjunction with medication, with testing and retesting of these. For some, this is a prolonged process with a need for multiple hospital visits and adjustments:

After the setting, it feels good for a day or two, and after that it starts to pull in my face, with pain in my chin. $\left(\right.$ Patient $\left.{ }^{28}\right)$

In some cases, this necessitates trade-offs, for example, between settings which optimise motor function or speech:

I have trouble speaking. I have to learn to live with that, because if the stimulation is adjusted to improve my speech, then I have trouble walking. (Patient ${ }^{24}$ )

This is also a time of testing the new boundaries and limits of physical and functional ability and engagement in activities.
Social transitions include redefinition of the boundaries of social activities and friendships. For some, relationships with spouses must also change. 'Normal' relationships are likely to have been lost during disease progression, as spouses take on and agree new roles within a relationship_carer as well as partner. Following surgery, couples may need to renegotiate roles. This is clearly a potential source of strain within relationships when consensus about new roles is difficult to attain:

... [we] were [the] perfect couple, since the operation he wants to live like a young man: going out, meeting new people...it's unbearable! I prefer him as he was before, always nice and quiet. (Spouse ${ }^{11}$ )

There are examples ${ }^{11} 192427$ of patients wanting to re-establish former roles and feeling that spouses are overprotective, as well as conflicting expectations. Spouses who see substantial improvements in motor function are disappointed when partners do not change behaviour accordingly. Patients report the persistence of symptoms and struggle with such physical transitions:

My wife cannot tell when I am feeling bad, and then she thinks I am lazy. She starts fussing, telling me to get my act together... and I try, but when I am in pain or in some other way cannot function, then there is nothing to do about it. (Patient ${ }^{24}$ )

Loss of initiative $\mathrm{e}^{11} 192427$ is noted in several of the papers. Despite improvement in motor disability, often this is not reflected in patients' behaviour, for example, they do not want to pursue new activities, or lack interest in work where previously it was a focus;

Before, I was absolutely determined to carry on working. For me, it was a way of fighting the illness. I wanted to show that I was still capable. After the surgery, I realised that there were more important things, like having time, or seeing my grandchildren grow up. (Patient ${ }^{19}$ )

Spouses are reported as drivers of change, encouraging patients to test the boundaries of their abilities, although as above, this can be a source of tension where change is not apparent: ${ }^{27}$

I am very alert that he doesn't get too comfortable...such as he asks me to get him things and I tell him to get up and get them himself. (Spouse ${ }^{27}$ )

Patients must cope psychologically with these transitions. There may be a hangover from the pre-DBS period that was characterised by unpredictability and loss of control, despite postsurgery improvements in motor function. The fear of the consequences of unpredictability may remain:

Even though I know my motor state is perfectly normal, I just can't get rid of the thoughts I used to have, when I was ill. I still have the same reflexes to initiate walking 
and the rituals before taking the medicine. I always refuse invitations to go out because I imagine I'll have freezing attacks and walking problems, even though it's no longer the case. My body is cured but my mind is still sick. (Patient ${ }^{11}$ )

This also appears to be a time when patients and spouses have not regained control over the management of the disease which is largely in the hands of the healthcare professionals who guide the adjustment of stimulation parameters.

Hope may be a key psychological contingency which influences the experience of these transitions.

\section{Hopes}

Although only labelled explicitly in one of the papers as a subtheme, ${ }^{24}$ hopes for the outcome and impact of DBS are implicit in much of these data. In the face of a significant history of loss and loss of control in late stage PD, hopes to counteract the progressive impact and decline associated with the disease are strong:

I think it will be easier...that is the impression I get...I think so...some talk of it as getting a new life [laughing] ...I don't need a new life, but an easier life wouldn't be so bad. $\left(\right.$ Patient ${ }^{26}$ )

The evidence suggests that patients do not necessarily know what to expect:

Nobody knows what happens after the operation, right? It is easier to relate to taking tablets and then you can go on again, but we don't know after the operation...It is like a new day 1. Like when I got ill-then life starts from there...so this will happen again on the $19^{\text {th }}$ [date of surgery] then life starts all over again...[laughs]. $\left(\right.$ Patient $\left.^{26}\right)$

However, this may not reflect a lack of information or understanding that sets 'expectations' too highly, as much as hopes to regain what has been lost:

I have experienced an overall improvement. I can walk, I can get in and out of bed, and I don't use my wheelchair anymore...that I had expected more is my fault, looking back, the expectations I had were unrealistic. There were no grounds for the improvements I had hoped for. But I had read interviews with patients who had had the operation, and they were all positive. They said nothing of the other side of the coin. And I read it as this was a miracle cure... and it is...but the miracles do stick to the ground. $\left(\right.$ Patient $\left.^{24}\right)$

There is also evidence of patients rejecting the cautious counselling of expectations from healthcare professionals, in favour of post-DBS accounts that align with hopes for particular outcomes:

They [the doctors] say not to expect too much, but I don't know. I think it will be good. I know somebody who has had it done and they are very satisfied, so why shouldn't I be? (Patient ${ }^{26}$ )

Patients may wish for further improvements during transitions via refinements in stimulation parameters:

Can't you move the electrodes a bit, a millimetre or less? Or at least increase the stimulation? I am sure it is possible to improve the parameters so that I feel better. $\left(\right.$ Patient $\left.^{11}\right)$

This may be inter-related with pre-DBS hopes for the procedure which are not necessarily realised fully for patients and spouses. In turn, there may be a need for psychological resolution and realisation that this is as good as it gets' in order to accommodate the post-DBS state. Haahr et $a l^{24}$ term this 'reconciliation'.

\section{DISCUSSION}

We have synthesised seven studies. ${ }^{11} 19{ }^{24-28}$ At present, this is a relatively small body of work, although it does represent in-depth qualitative investigation with patients from a range of settings and at a range of time points after DBS. Three of the papers stem from the same Danish data set. ${ }^{24} 2627$ Additionally, one of these papers ${ }^{24}$ was key in the early stages of the synthesis as it provided a conceptually rich account of the experience of DBS that aided the translation of studies into one another. Naturally, this requires reflection as to whether this one data set has skewed our synthesis and ultimately the interpretation and line of argument presented here. We do not believe this to be the case as the core concepts identified occur across the majority of the papers, thereby strengthening the case for the interpretation given. However, we acknowledge that there is a need for further primary research in different and varied settings and patient populations, to improve our knowledge in this area. In addition, there is a need to further examine spouses' experiences and insights. Only one of the papers we identified explored this in detail, ${ }^{27}$ which is a clear deficit of knowledge in this area. We included this study as we felt that it was able to shed valuable light on the experience of DBS, and also because other papers reported the impacts of DBS on aspects of relationships from a patient perspective. Two papers ${ }^{11}{ }^{19}$ were rated low quality based on methodological reporting but were conceptually rich. We included these in the synthesis as conceptual richness is recognised as a key indicator of the utility of individual studies for qualitative synthesis, and for metaethnography in particular. ${ }^{20}$

We suggest that normality is a core concept which facilitates understanding of the experiences of DBS. Normality is a complex concept that has been used to understand the patient experience of other diseases. For example, Sanderson $e t a l^{30}$ have used it as an explanatory tool for patients' experience of rheumatoid arthritis (RA), and it has also been used to understand patient perspectives on motor neuron disease (MND) ${ }^{31}$ Here, normality has 
a dual meaning and describes both a prediseased state and life, but also a state whereby patients and spouses are able to adopt an adjusted life accommodating the disease and its impacts. The latter has also been described as a form of 'normalisation' of disease in studies that focus on adaptation to chronic illness, whereby patients come to see and treat the illness as 'normal', 32 33 developing iterative strategies in the actions that they take in living with the illness. We propose that a sense of control is a condition for this form of normality in PD. Patients have lost this control in late stage PD and do not regain it immediately following surgery due to the complex multifaceted transitions that they face while adjusting to the post-DBS disease state. Hopes to regain what has been lost as a result of the illness and for further improvements via adjustment in stimulation may be key psychological contingencies for successfully negotiating these transitions, and attaining what we have called a 'new normality'. This is similar to what has been termed 'resetting normality' in RA and a 'dynamic normality' in MND. ${ }^{30} 31$

This way of conceptualising post-DBS patient experience provides a potentially explanatory framework for some of the observations in the trial and observational quantitative evidence. While negative assessments (eg, QoL; subjective ratings) by patients and spouses post-DBS $^{3489}$ may well have a biomedical component, it is crucial to acknowledge the complex transitions for patients and those around them. Patients are clearly not inexplicably struggling in the face of a seemingly miraculous recovery of motor function. Symptoms persist post-DBS during the transitions that are undertaken. Hopes may be key, and despite careful counselling and information giving to patients, they may retain hopes for the procedure that are unattainable. This has been observed in the use of DBS for treatment-resistant depression $^{34}$ and previously in DBS for PD. For example, Montel and Bungener (ref. 35, p. 109) comment:

\footnotetext{
...our clinical experience has led us to the conclusion that for many patients with PD who are to be treated with stimulation, their expectations are too unrealistic, which accounts for their disappointment 12 months later. Most of them consider the stimulation to be a "magic" process that is going to free them entirely from their physical impairment. When they are confronted with reality (namely, that they can be improved but not totally cured by stimulation), they are very disappointed. In fact, the problem is not the presentation of information about DBS by neurologists but rather the way the candidates interpret it. Most often, candidates "hear" what they want to hear, that is, that after the stimulation, they will return to life as it was before PD.
}

This may be a consequence of the loss and loss of control experienced prior to DBS, such that hopes to regain a predisease normality may outweigh 'reasoned' expectations for improvements.

Stimulation adjustment can be long and difficult. The prospect that such adjustment can realise further improvements that are not yet apparent may prolong hopes for outcomes (eg, normality) that cannot be realised, preventing patients from accommodating DBS as quickly as they may otherwise do. Patients may also fear testing the boundaries of their physical abilities, which is perhaps a psychological hangover from the impacts of previous motor function. This may not be immediately apparent to healthcare professionals, or even spouses. The latter are likely to be a key catalyst in change and support, but at the same time, there is a need for patients and spouses to adjust to new roles within their relationships.

The findings from meta-analysis, individual trial data and observational studies are reflected in this qualitative research. Negative social support, emotional well-being and communication outcomes seem well explained by the qualitative data. Measurement of outcomes in the short term (3 or 6 months) is likely to coincide with the transitions described, impacting on patient-reported outcomes, and implying that longer follow-up is required. Also, if key holistic assessments of the impacts of DBS are to be made, then outcome measures should ideally capture concepts such as normality and control. The predominant primary outcome measure used in DBS trials, PDQ-39, measures items in eight domains (mobility, activities of daily living, emotional well-being, stigma, social support, cognitions, communication and bodily discomfort). Each of these domains can be interpreted within the qualitative evidence via patients' and spouses' accounts of the impacts of DBS. This provides further validation that PDQ-39 does measure items of importance to patients and spouses, and within the context of DBS. While outcome measures such as PDQ-39 have been developed using primary qualitative data (in-depth interviews), ${ }^{36}$ our synthesis suggests that measures which capture the impact of treatments on control and normality may also prove useful.

At present, the body of qualitative evidence underpinning our knowledge of the experience and impact of DBS is small. Additional longitudinal investigation of the transitions described here is needed to further understand and facilitate these transitions. This should use mixed-methods research techniques featuring welldesigned qualitative investigation with patients and spouses, alongside quantitative data. Key areas for research are likely to include a focus on pre-DBS and post-DBS information giving and support; the experience of the stimulation adjustment process post surgery; the nature and role of social support during transitional periods including the impact on relationships; and the role of professional support throughout this period. Our findings also suggest the need for further reflection on the use of DBS earlier in PD progression, although this practice is currently being debated within the PD/DBS community. ${ }^{37} 38$ Using DBS at an earlier stage, when patients are able to maintain some control and normality, may be a similarly disruptive experience with need for equivalent transitions and loss of control during these. 


\section{CONCLUSIONS}

Our synthesis identifies five core concepts: normality, loss, loss of control, transitions and hopes which facilitate our understanding of the experience of DBS for patients and their spouses. There is a clear need for further research to explore the exact nature of the transitions described here and how best patients and their spouses can be supported by healthcare professionals and others, before, during and after DBS for PD. In assessing the impacts of DBS, and other treatments in late stage PD, we should consider how to capture the impacts on holistic concepts such as control and normality. Studies that examine the outcomes of DBS require longer term follow-up.

Contributors JM and LLJ conceived the idea for the research (in conjunction with $\mathrm{CR}$ and $\mathrm{CJ}$ ), conducted the initial review and data analysis, and wrote the first draft of the manuscript. SB designed and conducted the literature searches. RG advised on review design, conduct and presentation. All authors contributed to data interpretation and subsequent revisions to the manuscript. All authors have read and agreed the final version of the manuscript.

Funding This work was part funded by the Medical Research Council Midland Hub for Trials Methodology Research (Grant Number: G0800808). RG is partially supported by the National Institute for Health Research (NIHR) Collaboration for Leadership in Applied Health Research and Care (CLAHRC) for the South West Peninsula (PenCLAHRC).

Competing interests None.

Provenance and peer review Not commissioned; externally peer reviewed.

Data sharing statement No additional data are available.

Open Access This is an Open Access article distributed in accordance with the terms of the Creative Commons Attribution (CC BY 4.0) license, which permits others to distribute, remix, adapt and build upon this work, for commercial use, provided the original work is properly cited. See: http:// creativecommons.org/licenses/by/4.0/

\section{REFERENCES}

1. Schuepbach WM RJ, Knudsen K, Volkmann J, et al. EARLYSTIM Study Group. Neurostimulation for Parkinson's disease with early motor complications. N Engl J Med 2013;14:610-22.

2. Perestelo-Pérez L, Rivero-Santana A, Pérez-Ramos J, et al. Deep brain stimulation in Parkinson's disease: meta-analysis of randomized controlled trials. J Neurol 2014;261:2051-60.

3. Daniels C, Krack P, Volkmann J, et al. Is improvement in the quality of life after subthalamic nucleus stimulation in Parkinson's disease predictable? Mov Disord 2011;26:2516-21.

4. Soulas T, Sultan S, Gurruchaga JM, et al. Depression and coping as predictors of change after deep brain stimulation in Parkinson's disease. World Neurosurg 2011;75:525-32.

5. Diamond A, Jankovic J. The effect of deep brain stimulation on quality of life in movement disorders. J Neurol Neurosurg Psychiatr 2005;76:1188-93.

6. Drapier S, Raoul S, Drapier D, et al. Only physical aspects of quality of life are significantly improved by bilateral subthalamic stimulation in Parkinson's disease. J Neurol 2005;252:583-8.

7. Smeding HM, Speelman JD, Huizenga HM, et al. Predictors of cognitive and psychosocial outcome after STN DBS in Parkinson's disease. J Neurol Neurosurg Psychiatr 2011;82: 754-60.

8. Lewis CJ, Maier F, Horstkötter N, et al. The impact of subthalamic deep brain stimulation on caregivers of Parkinson's disease patients: an exploratory study. J Neurol 2015;262:337-45.

9. Maier F, Lewis CJ, Horstkoetter N, et al. Patients' expectations of deep brain stimulation, and subjective perceived outcome related to clinical measures in Parkinson's disease: a mixed-method approach. J Neurol Neurosurg Psychiatr 2013;84:1273-81.

10. Voon $\mathrm{V}, \mathrm{Krack} P$, Lang $\mathrm{AE}$, et al. A multicentre study on suicide outcomes following subthalamic stimulation for Parkinson's disease. Brain 2008;131:2720-8.
11. Agid $Y$, Schüpbach $M$, Gargiulo $M$, et al. Neurosurgery in Parkinson's disease: the doctor is happy, the patient less so? J Neural Transm Suppl 2006;70:409-14.

12. O'Cathain A, Thomas KJ, Drabble SJ, et al. Maximising the value of combining qualitative research and randomised controlled trials in health research: the QUAlitative Research in Trials (QUART) study —a mixed methods study. Health Technol Assess 2014:18:1-197.

13. Barnett-Page $E$, Thomas J. Methods for the synthesis of qualitative research: a critical review. BMC Med Res Methodol 2009;9:59.

14. Evans D. Database searches for qualitative research. J Med Libr Assoc 2002;90:290-3.

15. Shaw RL, Booth $A$, Sutton $A J$, et al. Finding qualitative research: an evaluation of search strategies. BMC Med Res Methodol 2004;4:5.

16. Barbour R. Checklists for improving rigour in qualitative research a case of the tail wagging the dog? BMJ 2001;5:1115-17.

17. Garside R. Should we appraise the quality of qualitative research reports for systematic reviews, and if so, how? Eur J Soc Sci Res 2014;27:67-79.

18. Critical Appraisal Skills Programme (CASP). Qualitative Research Checklist. Secondary Qualitative Research Checklist http://media. wix.com/ugd/dded87_29c5b002d99342f788c6ac670e49f274.pdf (accessed 31 May 2013)

19. Gisquet E. Cerebral implants and Parkinson's disease: a unique form of biographical disruption? Soc Sci Med 2008;67:1847-51.

20. Noblit GW, Hare RD. Meta-ethnography: synthesizing qualitative studies. Newbury Park, CA, USA: Sage, 1988.

21. Britten N, Campbell R, Pope C, et al. Using meta ethnography to synthesise qualitative research: a worked example. $J$ Health Serv Res Policy 2002;7:209-15.

22. Campbell R, Pound $\mathrm{P}$, Morgan $\mathrm{M}$, et al. Evaluating meta-ethnography: systematic analysis and synthesis of qualitative research. Health Technol Assess 2011;15:1-164.

23. Tong A, Flemming K, Mclnnes $\mathrm{E}$, et al. Enhancing transparency in reporting the synthesis of qualitative research: ENTREQ. BMC Med Res Methodol 2012;12:181.

24. Haahr A, Kirkevold M, Hall EO, et al. From miracle to reconciliation: a hermeneutic phenomenological study exploring the experience of living with Parkinson's disease following deep brain stimulation. Int $J$ Nurs Stud 2010;47:1228-36.

25. Ahlberg E, Laakso K, Hartelius L. Perceived changes in communication as an effect of STN surgery in Parkinson's disease: a qualitative interview study. Parkinsons Dis 2011;2011:540158.

26. Haahr A, Kirkevold M, Hall EO, et al. Living with advanced Parkinson's disease: a constant struggle with unpredictability $J$ Adv Nurs 2011;67:408-17.

27. Haahr A, Kirkevold M, Hall EO, et al. 'Being in it together': living with a partner receiving deep brain stimulation for advanced Parkinson's disease-a hermeneutic phenomenological study. J Adv Nurs 2013;69:338-47.

28. Hariz GM, Hamberg K. Perceptions of living with a device-based treatment: an account of patients treated with deep brain stimulation for Parkinson's disease. Neuromodulation 2014;17:272-8.

29. Soundy A, Stubbs B, Roskell C. The experience of Parkinson's disease: a systematic review and meta-ethnography. SCI World J 2014;2014:613592.

30. Sanderson T, Calnan M, Morris M, et al. Shifting normalities: interactions of changing conceptions of a normal life and the normalisation of symptoms in rheumatoid arthritis. Sociol Health IIIn 2011;33:618-33.

31. Brown J, Addington-Hall J. How people with motor neurone disease talk about living with their illness: a narrative study. J Adv Nurs 2008;62:200-8.

32. Bury M. The sociology of chronic illness: a review of research and prospects. Sociol Health IIIn 1991;13:451-68.

33. Bury M. IIIness narratives: fact or fiction? Sociol Health IIIn 2001;23:263-85.

34. Johansson V, Garwicz M, Kanje M, et al. Beyond blind optimism and unfounded fears: deep brain stimulation for treatment resistant depression. Neuroethics 2013;6:457-71.

35. Montel SR, Bungener C. Coping and quality of life of patients with Parkinson disease who have undergone deep brain stimulation of the subthalamic nucleus. Surg Neurol 2009;72:105-10.

36. Jenkinson C, Fitzpatrick R, Peto V, et al. The Parkinson's Disease Questionnaire (PDQ-39): development and validation of a Parkinson's disease summary index score. Age Ageing 1997;26:353-7.

37. Charles D, Konrad PE, Neimat JS, et al. Subthalamic nucleus deep brain stimulation in early stage Parkinson's disease. Parkinsonism Relat Disord 2014;20:731-7.

38. Hariz M. There is no credible rational for deep brain stimulation in very early Parkinson's disease! (Comment). Parkinsonism Relat Disord 2015;21:345-6. 